Solar

Collectior

development

BY ATWOOD R. HEATH JR.

NASA Langley Research Center and PRESTON T. MAXWELL

NASA Headquarters

\section{High interest}

in solar electric

power systems

motivates

continued study

and experiments

with rigid

collectors in

both large sizes

and modular

combinations
The variety of methods under development for conversion of thermal (solar) energy to electricity have stimulated a broad parallel interest in the development of solar collectors. Such devices must concentrate the relatively low-level solar energy (about $130 \mathrm{w} / \mathrm{sq} \mathrm{ft}$ at the earth's orbit in space) to a usable density (temperature) for the particular energyconversion method to be employed.

As with most things, whether technical, political, or spiritual, there are proponents of many alternative methods and materials for the fabrication of solar collectors, each of which may be shown to have advantages for particular applications. Thus, it appears worthwhile to list the principal factors which must be weighed or considered. This might be done, not necessarily in order of importance, as follows:

- Operating temperature of the energy-conversion device or system.

- Efficiency.

- Weight per unit projected area.

- Specific power: thermal energy per unit weight at a specific temperature.

- Prelaunch storage volume and deployment method.

Many other factors must be considered, such as structural integrity and stiffness, potential optical degradation due to thermal gradients and space-environment effects, scalability to higher power levels, requirements for masters, and magnetic properties.

Within this framework, we can attempt an assessment of the state of the art of solar collectors (concentra- None tors).

On page 59 there appear sketches of Cat-os six different concepts of lightweight solar-energy collector, ${ }^{1}$ not the only ones being considered, but those developed to a point where quantitative data on their capabilities exist. Examples of the six types are listed in the associated table, with some pertinent characteristics. All are paraboloids, except for the Fresnel, which is essentially a flat collector made up of annuli of paraboloids having a common focus. A description of each, with some details of materials and methods of fabrication, follows.

The Fresnel collector illustrated has four hinged panels. ${ }^{2}$ The Fresnel surface is made by electroforming nickel on a steel master that has been machined and polished. The Fresnel electroform is then bonded to an electroformed stiffening structure.

Shown next is one form of inflatable, pressurized collector. ${ }^{2}$ It is formed of an aluminized Mylar paraboloid and a clear Mylar front cover. An inflated torus also made of Mylar attaches to the outside of the collector at the junction of the reflecting surface and the front cover.

Next appears a sketch of the inflatable-rigidized collector.,4 Basically an aluminized plastic paraboloid, it would be made rigid in space by the application of a foamed plastic to its back.

The one-piece collector ${ }^{5,6}$ can be made by electroforming a thin dish of nickel on an appropriate master, the dish then being stiffened by the ad-

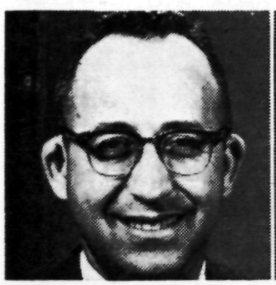

A. R. HEATH JR. aerospace engineer. is responsible for a major part of the NASA program which investigates existing
developments and guides research on techniques to use energy from the sun.

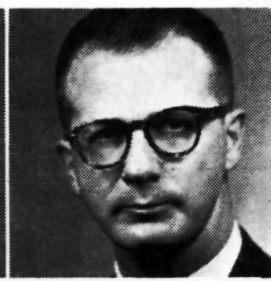

P. T. MAXWELL

heads NASA's Solar Dynamics Projects. Active for several years in development application, and test of space electrical power systems, he has been associated with NASA since 1960 .

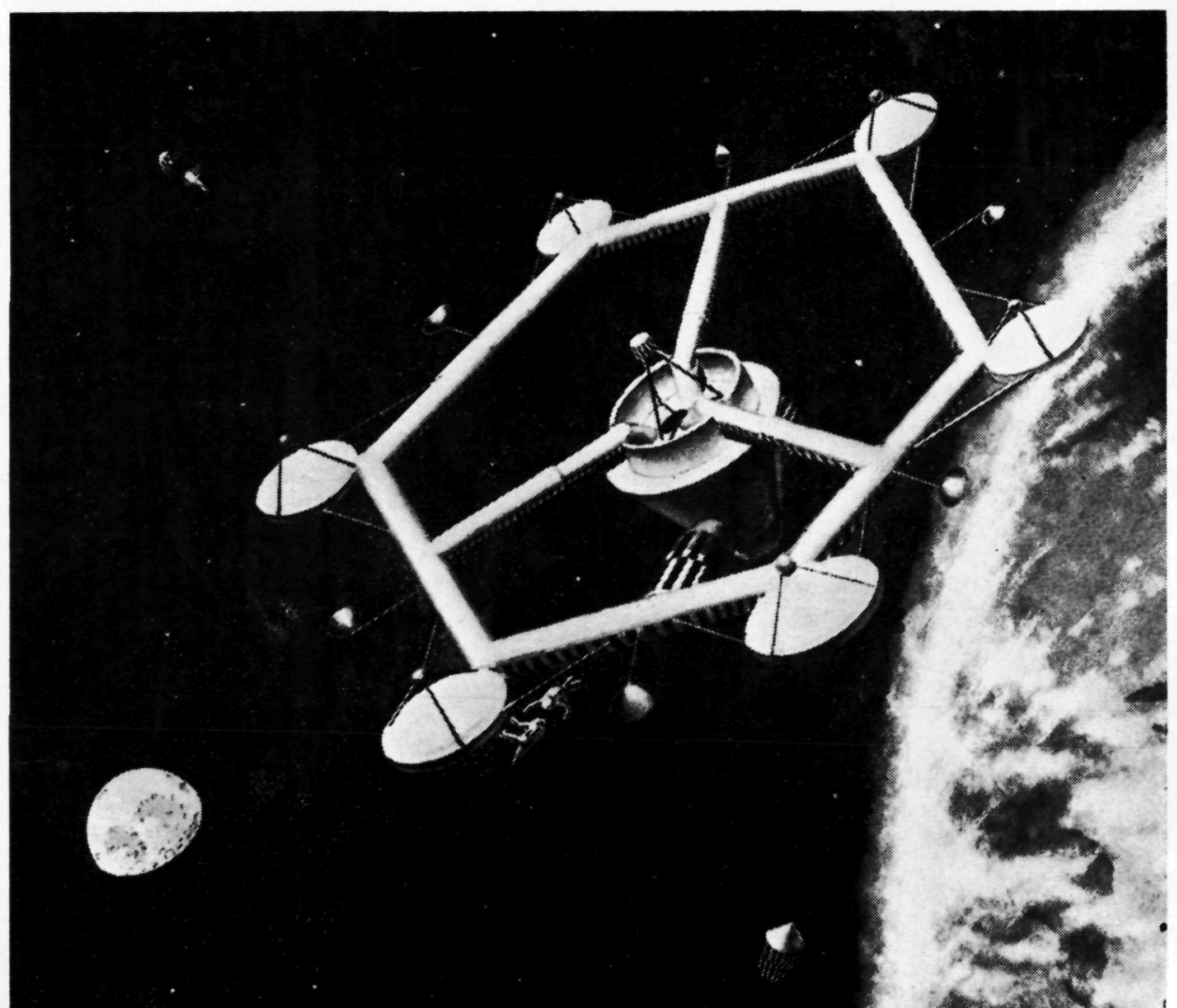


dition of an electroformed torus to its periphery. Another construction involves a cast epoxy-plastic reflecting surface bonded to an aluminum honeycomb, this in turn backed up by a plastic Fiberglas panel. The reflective face can be cast on any suitable convex master. Several collectors have been so made. ${ }^{7}$ One-piece collectors have also been made by such methods as spin-casting of plastic, ${ }^{8}$ hydroforming of aluminum, and stretch-forming of aluminum; but complete quantitative data on the capabilities of these are not currently available.

Petal collectors exist in several variations, all having in common a hub with attached petals, which fold up to form a compact package for launching. Springs, cables, or mechanical linkages deploy these devices. Several have been built, and different methods have been used in the construction of the petals for each. One had petals of electroformed nickel, monocoque construction. ${ }^{2}$ Two others had sandwich petals of an aluminum reflecting face, honeycomb, and back. ${ }^{8.10}$ Another ${ }^{11}$ had petals formed of a thin aluminum face stiffened by a light aluminum lattice truss spotwelded to the back.

The last sketch shows an umbrella collector, ${ }_{-1}^{13}$ consisting of an aluminized Mylar skin stretched over metal ribs, and with an operational pneumatic erecting mechanism.

Among its important characteristics, a collector must gather solar radiation efficiently and provide the desired degree of concentration of the radiation commensurate with ability of the con- version system to use the heat. The first graph on page 60 shows efficiency as a function of concentration ratio for the six collector concepts. The efficiencies have been measured with cold calorimeters, which minimize reradiation, so that the values are essentially only a function of collector geometry and specular reflectivity. The concentration ratio is based on the ratio of the projected reflective area of the collector to the aperture area of a cavity heat absorber. For a spherical absorber, the surface of the sphere forms the latter area.

Shown as a goal is a theoretical curve for a paraboloidal collector with a reflectivity of $0.91-\mathrm{a}$ value that might be obtained from a highly polished surface with a coating of vacuum-deposited aluminum exposed to the solar spectrum. The one-piececollector data closely approach the theoretical curve, which indicates that the master was of good quality and the reproduction process was faithful.

Four collectors fall in roughly the same range of concentrating ability, but with rather widely various effciencies. This failure to approach the theoretical potential can be attributed to conceptual, material, or fabrication problems. The petal collector had honeycomb markoff on the reflective face, as well as some problems with reflective surface finish. The inflatablerigidized collector had a reflectivity of only 0.83 , which is the value for aluminized Mylar plastic, and an "orange peel" effect caused by the foam backing was apparent. These two collectors were designed, however, for

\section{EXAMPLES OF FABRICATED SOLAR GOLLEGTORS}

\begin{tabular}{|c|c|c|c|c|c|}
\hline Type & $\begin{array}{l}\text { Method of } \\
\text { construction }\end{array}$ & Material & $\begin{array}{l}\text { Rim } \\
\text { angle, } \\
\text { deg }\end{array}$ & $\underset{\mathrm{ft}}{\text { Diam. }}$ & $\begin{array}{c}\text { Unit } \\
\text { welght, } \\
\text { lb/ft' }\end{array}$ \\
\hline $\begin{array}{l}\text { Fresnel: } \\
\text { Inflatable } \\
\text { Inflatable } \\
\text { rigidized } 3,4\end{array}$ & $\begin{array}{l}\text { Electroformed } \\
\text { Stretch-formed } \\
-\end{array}$ & $\begin{array}{l}\text { Nickel } \\
\text { Mylar } \\
\text { Mylarfoam }\end{array}$ & $\begin{array}{l}40.00 \\
53.13 \\
60.00\end{array}$ & $\begin{array}{r}4.00 \\
4.27 \\
10.00\end{array}$ & $\begin{array}{l}0.46 \\
0.08^{\mathrm{a}} \\
3.82\end{array}$ \\
\hline $\begin{array}{l}\text { One plece } \\
\text { Petal }\end{array}$ & $\begin{array}{l}\text { Electroformed } \\
\text { Stretch-formed }\end{array}$ & $\begin{array}{l}\text { Nickel } \\
\text { Aluminum } \\
\text { honeycomb }\end{array}$ & $\begin{array}{l}61.50 \\
52.00\end{array}$ & $\begin{array}{r}5.50 \\
32.20\end{array}$ & $\begin{array}{l}0.96 \\
0.18^{\mathrm{b}}\end{array}$ \\
\hline Umbrella 12 & 60 aluminum ribs & Mylar & 90.00 & 10.00 & $0.11^{\circ}$ \\
\hline
\end{tabular}

a Mylar only.

"Ribs and Mylar only.

\section{SOLAR-COLLECTOR CONFIGURATIONS}
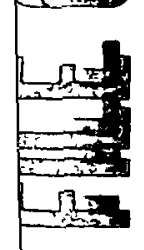

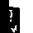

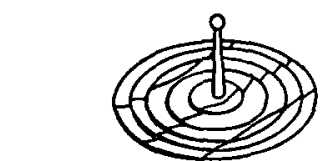

Fresnel

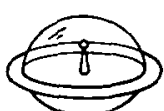

Inflatable

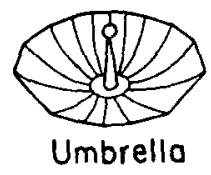

use with mechanical systems, and did not require high concentrating ability. The Fresnel collector, of course, has an inherent shadowing problem that amounts to about 0.14 loss in efficiency; in addition, some undetermined loss occurred which could be caused by difficulties in polishing the master. The low efficiencies of the inflatable collector were attributed to large transmission and reflectance losses from the front face as well as the reflecting face. The umbrella collector shows very low concentrating ability because the reflecting-surface gores between the metal ribs take a nonparaboloidal shape.

To find its temperature capability, a collector must be combined with an absorber that radiates at its operating temperature. For purpose of comparison, a cavity absorber is assumed with an absorptivity and emissivity of 1.00 ; the solar constant, which affects the re-radiation term, is assumed to be $130 \mathrm{w} / \mathrm{sq} \mathrm{ft}$. Then the efficiency data given in the first graph are combined with the re-radiation losses of the assumed absorber to obtain the combined efficiency as a function of temperature, as shown in the second graph. If a thermionic-conversion system with operating temperatures near 4000 . R_is_required, only the_one-piece mirror is capable of efficient operation at the present time. All of the expandable collectors are relatively inefficient even at temperatures around $2000 \mathrm{R}$.

One of the principal aims of development to date has been to construct practical collectors of minimum weight. The third graph shows results of these efforts. Only the petal collector has been built in enough sizes so that the variation of unit weight with diameter can be determined: It runs essentially constant at about $0.20 \mathrm{lb} / \mathrm{sq} \mathrm{ft}$, except for one model at about $1.0 \mathrm{lb} / \mathrm{sq} \mathrm{ft}$. This was basically a ground-test model, and so not representative of a flight article. Construction of the one-piece collectors has been restricted mostly to one diameter $(5 \mathrm{ft})$ because of the availability of masters in this size. The unit weights vary quite widely-from 0.40-1.04 lb/sq ft-with the collectors having the lower weights also having poorer geometry. An estimated weight curve is given for the inflatablerigidized collector because the groundtest model had a unit weight of 3.82 $\mathrm{lb} / \mathrm{sq} \mathrm{ft}$ and this does not indicate the weight of a model to be used in space. Estimated unit weight is also shown for the umbrella collector. ${ }^{18}$ Good agreement appears between 5- and 10ft models. No variation in unit weight with collector diameter is available for Fresnel and inflatable collectors.

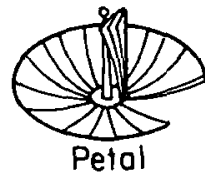

Inflatable-rigıdized 


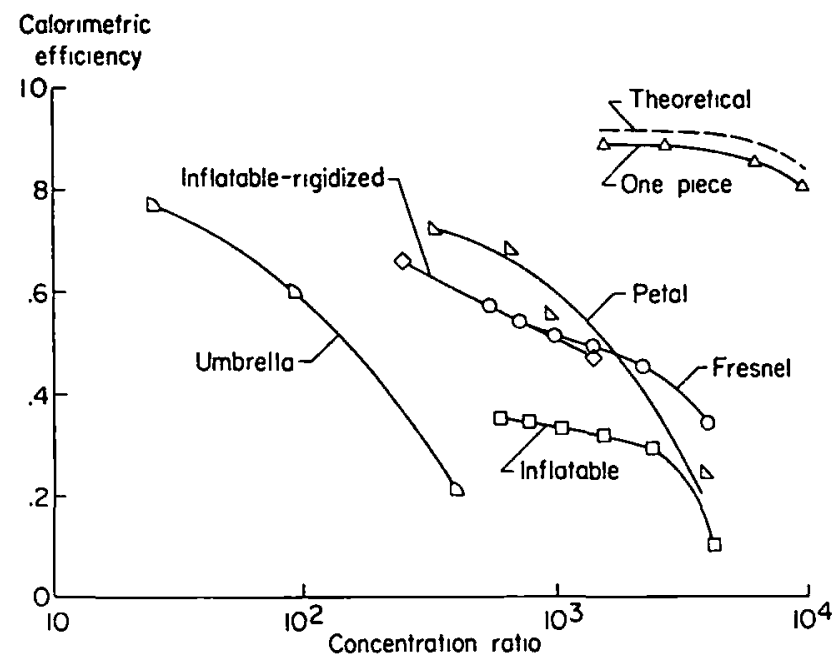

\section{COMBINED COLLECTOR-ABSORBER EFFICIENCY}

Combined collecior -

absorber efficiency

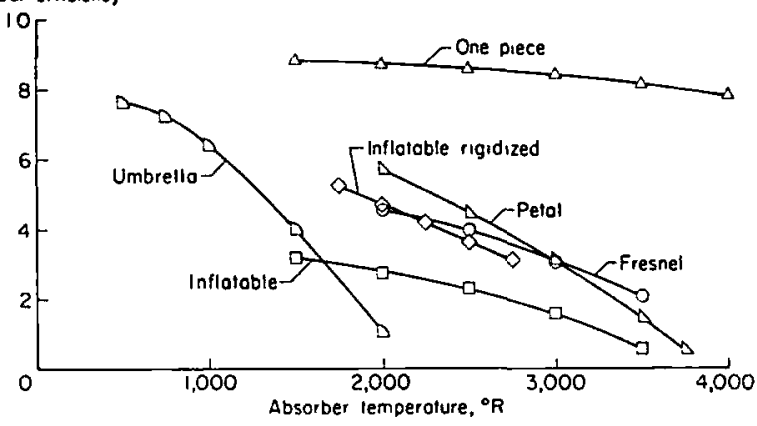

COLLECTOR SPECIFIC POWER

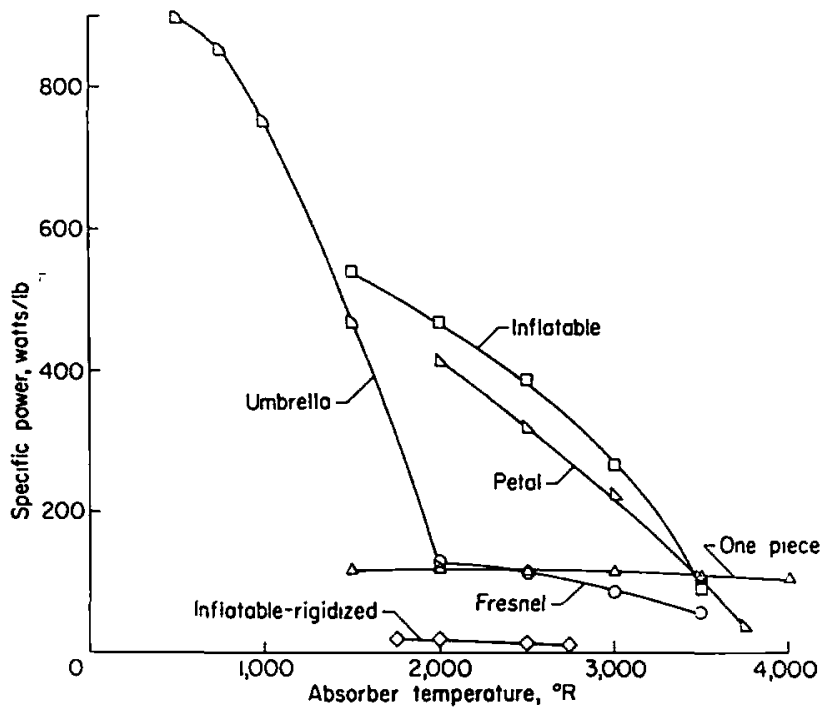

COLLECTOR PAGKaged VOLUME

\section{COLLECTOR UNIT WEIGHT}
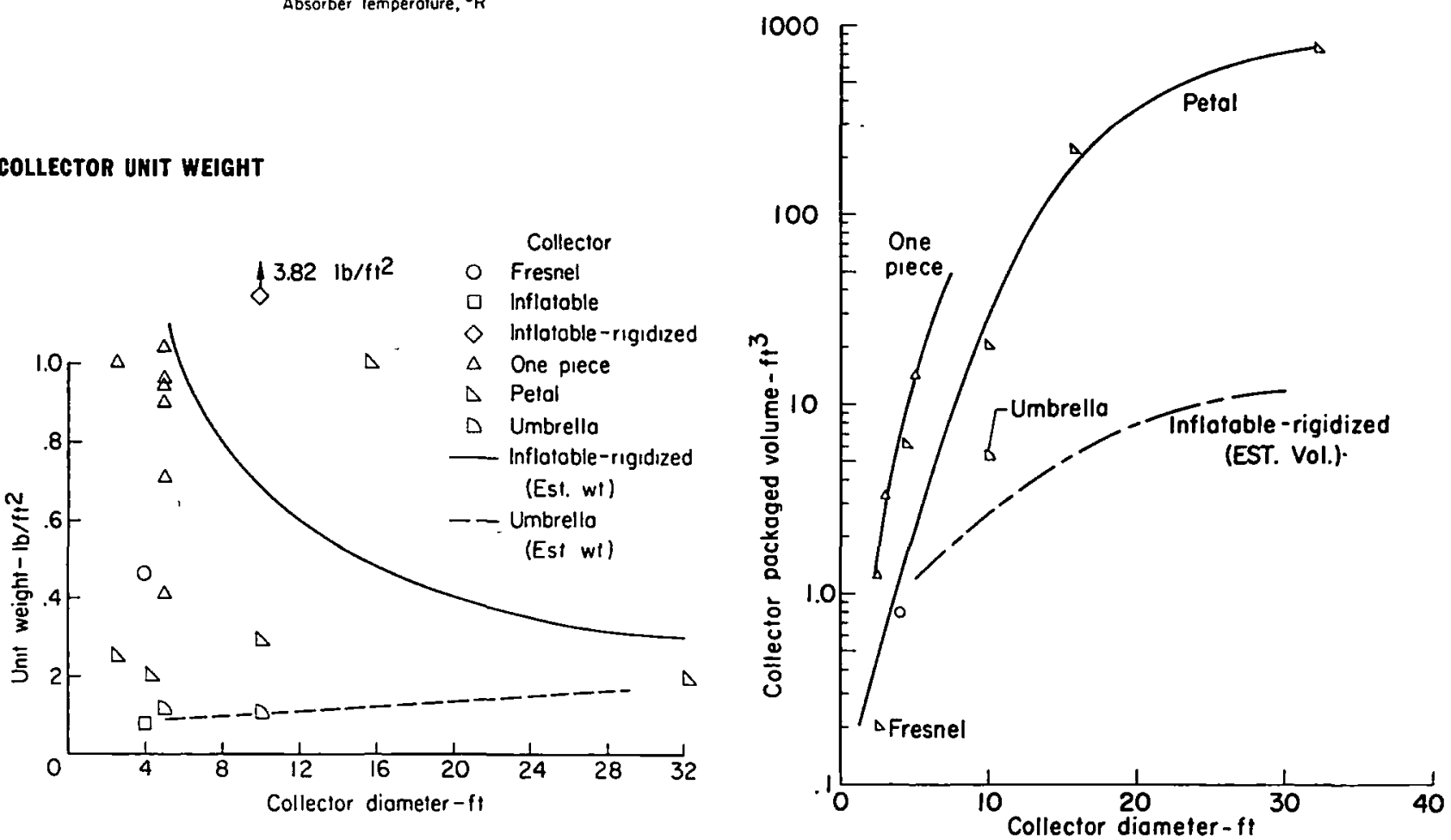
The selection of a collector for a given power-conversion system might well be based on the specific powerthe ratio of power to unit weight. A graph on page 60 shows the values of specific power for the six typical collectors. The combined collector-absorber efficiencies shown on that page were used with the unit weights of the various collectors and a solar constant of $130 \mathrm{w} / \mathrm{sq} \mathrm{ft}$ to obtain the values shown.

In the temperature range of 1500 $3500 \mathrm{R}$, the inflatable collector delivers the most power per pound due to its extremely low unit welght. On the other hand, the very efficient one-piece electroformed collector has a relatively low specific power due to its heavier unit weight. When comparing these two collectors at the same value of specific power, however, the inflatable would have an area many times that of the one-piece collectors for power systems of the same output. This fact brungs up another important consideration: Large-area collectors of low efficiency may well be undesirable because of possible interference with communications or other essential spacecraft functions. Thus the systems engineer may have no choice but to select the most efficient collector even at the expense of increased weight.

Each collector developed to date, with the exception of the one-piece type, has a folding or stowing feature for compactness during launch. The final graph on page 60 gives packaged volumes of the various types.

The one-piece collectors show highest volume for a given diameter. Of course, the limiting factor for onepiece models is generally the launchvehicle diameter, and so the packaged volume as determined could be relatively meaningless. The petal collectors are the next highest in volume, which runs to over $700 \mathrm{cu}$ ft for a 32.2 -ftdiam collector. Minor reduction in the volume of this type might be made, but no radical reduction is expected. The umbrella type has a fairly low volume, at least for the $10-\mathrm{ft}$ model, and the Fresnel volume is very low for the 4-ft model. A curve of the estimated volume of the inflatablerigidized collector is given to indicate what can be expected with it.

In considering objectuves for continued development of solar collectors in the near future, certain assumptions must be made. First, it appears that future solar-collector development efforts for thermal-electric application should emphasize the temperature range from about 1000 to about 4000 $R$, because conversion efficiencies for systems operating below about $1000 \mathrm{R}$ may be expected to be relatively low, requiring excessively large solar-collector areas, even though low temperatures may be attainable at rela tively low collector weights.

Second, it appears that near-future planning for solar-electrical power systems should be based on an exten sion of power levels to about $25 \mathrm{kw}$ thus requiring collectors in the $50-100$. ft-diam range.

Third, even as alternative thermalenergy sources such as isotopes and nuclear reactors become operational as flight systems, it is expected that a continuing requirement will exist for solar-electric systems, due to considerations of cost, weight, and personnel safety in special applications.

To be more specific, it is expected that the rigid parabolordal concentrator will continue for some time to be the only practical approach to thermonic operatıng temperatures (about $4000 \mathrm{R}$ ) with reasonable concentrator-absorber efficiencies. In concentrators of this type, a diameter of approximately $10 \mathrm{ft}$ is foreseeable with reasonable confidence. The extension of rigid concentrator sizes above 10-ft diam should not, however, be ruled out at this time, as future launch vehicles will permit rigid concentrators of $20-\mathrm{ft}$ diam or larger if the requirement for these arises.

Régarding fäbrication methō $\bar{s}$ and materials, the future is expected to see a continuing investigation of alternatives to the electroformed nickel concentrator which, while generally agreed to be at a relatively high state of development, has certain limitations, such as high weight and undesirable magnetic properties. For thermionic systems supplyıng relatively large amounts of power, it is expected that the trend will be to modular systems-multiple concentrators-as shown in the concept illustrated on page 58 .

For solar dynamic systems (operating temperature about $1800 \mathrm{R}$ ), a central energy-conversion system and a single concentrator would be considerably more advantageous than the modular approach envisioned for highpower thermionic systems. Consequently, as the power level increases, a comparable increase in solar-concentrator size will be necessary. Up to about 50-ft diam, the petal, Fresnel, and inflatable-rigidized types appear potentially suitable. Although the petal type, in this size range, may be somewhat closer to full-scale ground tests (the $32-\mathrm{ft}$ Sunflower concentrator ${ }^{13}$ ), it must be emphasized that a clear-cut choice of deployable concentrators below about $50-\mathrm{ft}$ diam is not possible at this time.

Above $50-\mathrm{ft}$ diam, it appears that the prelaunch stowage problems, and structural stresses during launch and in ground handling, will necessitate going to an inflatable-rigidized concentrator. Further, while it must be recognized that many uncertainties are associated with the technology for rigidizing a large, inflatable optically accurate structure in space, the potential usefulness and need for this capability will dictate a continuation of the current development effort.

Finally, it is generally agreed that the technology for solar concentrators does not appear to be the pacing factor in the development of solar-thermal electric power systems. None theless, since other components of the system may be more readily scalable to larger sizes than the solar concentrators, we cannot be assured that this situation will persist. For this reason, an energetic continuation of the research and development effort to extend the technology for solar concentrators will be essential, the level of effort and areas of emphasis being largely influenced by trends and developments in the related energy-conversion methods and devices

\section{References}

1 Heath, Atwood R. Jr, "Status of Solar Energy Coilector Technologv," Prepnnt No 2531-62. ARS Space Power Systems Conference, Sept 25-28, 1962

2. Sprnnger, Lee M, "Study, Design, and Fabrication of Solar Energy Concentrator Models," EOS Report 1577-Final, Electro-Optical Systems, Inc, Sept 1961 .

3 Tanenhaus, Abraham M “Inflated-Rigid3 Tanenhaus, Abraham $M$, "Inflated-Rigid-
zed Paraboloidal Solar Energy Concentrator Evaluation," GER-10295 Goodyear Aircraft Corp, July' 20, 1961.

4. "Quarterls Progress Reports of $15-\mathrm{KW}$ Development Program." Sundstrand Reports Nos CDRD-61.5008, CDRD-61 5011, CDRD615014 , CDRD-62 5015, CDRD-62.5016, CDRD-62 5017.

5. Menetrey, W. R., "Solar Energy Therm 5. Menetrey, W. R., "Solar Energv Thermionic Conversion System," EOS Report $1850-$
Final, Electro-Optical Systems, Inc., Jan. 1962 6 Pichel, M A, "Research and Development Techmques for Fabncation of Solar Concentrators," EOS Report 1587-Final, Electro-Optical Svstems, Inc, Dec 1961

7. Gillette, Roger B. and Snyder, Howard E. "Development and Testing of Lightweight Solar Concentrators," Document No D2-10107, Boeing Airplane Co, June 1961 Revised Dec 1961 ing Airplane Co, June 1961 Revised Dec 1961
8. Castle, Charles H, "Solar Concentrator 8. Castle, Charles H "Solar Concentrator
Development Status at TRW," Technical Memo 3345-68 TAPCO DIV of Thompson-RamoWooldndge, Inc , Feb 1962

9 Ferrara, Joseph $\mathbb{R}$, "A Solar Thermoelectric Generator System Study," ASD Tech. Report 61-315, USAF, Nov 1961 .

10 Cuthbert, D. J.. Purdy, D L., Whllams, E. W., Ruff, J A, Kerr, D. L Flanigan, W. $G$, Luck, R. Jr, Jones, D., and Baum, E. "Solar Thermonic Electrical Power System," Tech. Doc Rept. ASD-TDR-62-94, USAF, March 1962

11. Sandborn, D S, "The Development of Deployable Solar Concentrators for Space Power," Rvan Aerospace, presented at SAE Aerospace Engineering and $\mathrm{Mfg}$ Meeting, Oct 1961

12 Nowlin, Wullam $D$ and Benson, Harold E. "Study of an Erectable Parabolondal Solar E. "Studs of an Erectable Paraboloidal Solar Auvhary Power," NASA TN D-1368, 1962. 13 Rudy, J A and Picking, J. W., "Sunflow er Thermo-Dynamic Power System Development Status," Preprint No. 2502-62, ARS Space Power Systems Conference, Sept. 25-28, 1962. 